\title{
What mediates the racial/ethnic disparity in psychosocial stress among breast cancer patients?
}

\author{
C. T. Sánchez-Díaz ${ }^{1}$ (1) - S. Strayhorn ${ }^{3} \cdot$ S. Tejeda ${ }^{3} \cdot$ G. Vijayasiri ${ }^{3} \cdot$ G. H. Rauscher ${ }^{1,2} \cdot$ Y. Molina $^{2}$
}

Received: 7 May 2020 / Accepted: 5 January 2021 / Published online: 9 February 2021

(c) The Author(s) 2021

\begin{abstract}
Background Prior studies have observed greater levels of psychosocial stress (PSS) among non-Hispanic (nH) African American and Hispanic women when compared to $\mathrm{nH}$ White patients after a breast cancer diagnosis. We aimed to determine the independent and interdependent roles of socioeconomic position (SEP) and unmet support in the racial disparity in PSS among breast cancer patients.

Methods Participants were recruited from the Breast Cancer Care in Chicago study $(n=989)$. For all recently diagnosed breast cancer patients, aged 25-79, income, education, and tract-level disadvantage and affluence were summed to create a standardized socioeconomic position (SEP) score. Three measures of PSS related to loneliness, perceived stress, and psychological consequences of a breast cancer diagnosis were defined based on previously validated scales. Five domains of unmet social support needs (emotional, spiritual, informational, financial, and practical) were defined from interviews. We conducted path models in MPlus to estimate the extent to which PSS disparities were mediated by SEP and unmet social support needs.

Results Black and Hispanic patients reported greater PSS compared to white patients and greater unmet social support needs ( $p=0.001$ for all domains). Virtually all of the disparity in PSS could be explained by SEP. A substantial portion of the mediating influence of SEP was further transmitted by unmet financial and practical needs among Black patients and by unmet emotional needs for Hispanic patients.

Conclusions SEP appeared to be a root cause of the racial/ethnic disparities in PSS within our sample. Our findings further suggest that different interventions may be necessary to alleviate the burden of SEP for nH AA (i.e., more financial support) and Hispanic patients (i.e., more emotional support).
\end{abstract}

Keywords Racial/ethnic disparities · Psychosocial stress · Breast cancer

\section{Introduction}

Receiving a breast cancer diagnosis can lead to psychological social stress (PSS; e.g., negative perceptions about illness consequences, distress, loneliness), which has been associated with worse health-related quality of life (QOL),

C. T. Sánchez-Díaz

csanch56@uic.edu

1 Division of Epidemiology and Biostatistics, School of Public Health, University of Illinois at Chicago, 1603 West Taylor Street, Chicago, IL 60612, USA

2 Division of Community Health Sciences, School of Public Health, University of Illinois at Chicago, Chicago, USA

3 Institute for Health Research and Policy, University of Illinois at Chicago, Chicago, USA physiological side effects, and treatment decisions [1, 2]. Non-Hispanic African American (nH AA) and Hispanic women experience greater PSS and adverse consequences associated with breast cancer, when compared to non-Hispanic White (nH White) women in the USA [3-11].

Socio-ecological models are among the most popular theoretical frameworks for understanding racial/ethnic disparities in breast cancer and include multiple potential mechanisms at different levels $[12,13]$. For the current study, we focus on two major, well-studied determinants-low socioeconomic position (SEP) and unmet social support needs. Here, SEP is defined according to patients' level of resources and prestige when compared to others and is conceptualized as a wide-ranging concept that can be assessed at the individual, household unit, neighborhood, or community $[14,15]$. Social support is defined as a positive interaction 
wherein patients are helped by someone within their network [16]. These potential determinants are often treated analytically as independent, sometimes competing mediators [9-11, 17]. Existing work that has considered SEP and unmet social support needs simultaneously has been mixed, with some studies suggesting that unmet social support needs explain more of racial/ethnic cancer disparities [10], other work suggesting SEP explains more of racial/ethnic disparities [11], and other work has suggested both are important [17].

One reason for conflicting findings may be interdependent effects, posited by several theoretical frameworks. Specifically, SEP is theorized to be a root cause of disparities, wherein it may directly affect BC outcomes and indirectly influence them through other determinants, including unmet social support $[13,18]$. Through this theoretical lens, racial/ ethnic minorities are subject to low SEP due to historic and contemporary systemic marginalization. Disparities in SEP may lead to racial/ethnic minorities' disproportionate exposure to challenging interpersonal dynamics within medical settings (e.g., access to limited and inadequate support services) and community contexts (e.g., overburdened social networks, multiple completing support needs). Lower SEP and associated greater exposure to under resourced environments may consequently lead to lower perceived social support among racial/ethnic minorities, resulting in worse PSS.

Little to no research has quantified the interdependence between these mediating factors on racial/ethnic disparities in breast cancer.

Overall, we need research that expands on past research and examines the relative independent and interdependent effects of co-occurring, important mechanisms of racial disparities in breast cancer. To address this need, in the present study, we used population-based data from the Breast Cancer Care in Chicago study to evaluate the role of SEP and five domains of social support in explaining racial/ethnic disparities in PSS among breast cancer survivors. Specifically, we will address this gap by examining the independent and interdependent mediating paths by which SEP and unmet social support needs contribute to racial/ethnic disparities in breast cancer.

\section{Methods}

The Breast Cancer Care in Chicago (BCCC) was a population-based, cross-sectional study of newly diagnosed breast cancer patients $(n=989)$. The study has been described in detail elsewhere [10, 19, 20]. Eligible BCCC participants were women between 25 and 79 years of age at diagnosis, who self-identified as $\mathrm{nH}$ white $(n=397), \mathrm{nH}$ AA $(n=411)$, or Hispanic $(n=181)$, resided in Chicago and were diagnosed with a first primary breast cancer (in situ or invasive) between 2005 and $2008(n=981)$. The study received approval from the Institutional Review Board at the University of Illinois at Chicago and the Illinois Department of Public Health.

\section{Measures}

\section{Psychosocial stress (PSS)}

PSS was defined based on three existing validated scales. Four items from the Cohen Perceived Stress Subscale were summed to create a continuous perceived stress measure with an inter-item reliability (Cronbach's alpha) $=$ of 0.74 ) (0.81, $0.71,0.64$ for $\mathrm{nH}$ White, nH NH AA and Hispanic patients, respectively) $[21,22]$. Three items from the UCLA Felt Loneliness Scale (Cronbach's alpha $=0.79)(0.79,0.76$ and $0.83 \mathrm{nH}$ White, $\mathrm{nH}$ AA and Hispanic, respectively) [23], and 12 items from the Cockburn Psychological Consequences Scale (Cronbach's alpha $=0.93))(0.79,0.76$ and 0.83 for $\mathrm{nH}$ White, $\mathrm{nH}$ AA and Hispanic, respectively) were also summed [24] to define additional measures of PSS. For descriptive analysis, each PSS measure was dichotomized at the sample median.

\section{Socioeconomic position (SEP)}

SEP was defined using: (1) educational completion defined in years; (2) annual household income; and (3) two measures of SEP based on each woman's census tract of residence (concentrated disadvantage or concentrated affluence) [19]. Concentrated disadvantage was defined as the percentage of families in the census tract with incomes below the poverty line; percentage of families receiving public assistance; percentage of persons unemployed; and percentage of femaleheaded households with children. Concentrated affluence was measured by percentage of families with incomes of $\$ 75,000$ or more; percentage of adults with a college education or more; and percentage of the civilian labor force in professional and managerial occupations. Each measure of disadvantage and affluence was defined by creating an equally weighted sum across the relevant variables, then standardizing the sum to have a mean of 0 and a standard deviation of $1[10-12,25]$.

\section{Social support}

We considered five specific domains of social support: emotional, spiritual, informational, financial, and practical [16]. Emotional support is defined here as providing patients with empathy, love and trust. Spiritual support is defined as providing patients with religious- or faith-based care. Financial support is defined as providing patients with financial/ economic assistance. Informational support is defined as 
providing patients with necessary, helpful information. During the interview, the following script was read: "The next section of our interview concerns: help and support. People often need help or support when they have serious health problems. I am going to ask you some questions about how much help or support you needed and received since you were diagnosed with breast cancer." Patients were first asked, "Since you were diagnosed with breast cancer, how much emotional help or support have you needed? Would you say none, a little, some, or a great deal?" This question was followed with, "How much emotional help or support have you received, from anyone?" Women rated how much help or support they needed $(1=$ none, $4=$ a great deal $)$ and how much they received since their diagnosis for the five specific domains. The difference between needed and received support was calculated to define a variable representing unmet social support for each of the five specific areas. These variables were then categorized as greater than zero (presence of unmet support need) and less than or equal to zero (absence of unmet support need) [10].

\section{Participant characteristics}

Race/ethnicity was self-reported as nH White, $\mathrm{nH}$ AA and Hispanic. Age at diagnosis was defined in years and categorized as $<50,50-59$ and $60-79$ for descriptive analyses. Stage at diagnosis was categorized into American Joint Committee on Cancer categories of 0, I, II, III, and IV. Binary variables for initiation of chemotherapy, radiation and hormone therapy were defined for this study from a combination of self-reports and medical records [26].

\section{Statistical analysis}

\section{Descriptive analysis}

We tabulated the distribution of patient SEP and clinical factors by race/ethnicity (Table 1) and associations with measures of psychological stress (Table 2). We also obtained $p$ values from a chi-square tests of association for nominal covariates and from a test for trend for ordered covariates. We then estimated Y-standardized linear regression coefficients for the age-adjusted association of the three psychosocial stress measures comparing $\mathrm{nH}$ AA versus $\mathrm{nH}$ White and again comparing Hispanic versus $\mathrm{nH}$ White. Coefficients were Y-standardized in order to be able to make fair comparisons regarding the magnitude of associations between PSS measures (Table 3).

\section{Path models}

Path models were estimated using Mplus, version 8 [27] to examine the mediating role of unmet social support needs and SEP in explaining the racial disparities in all three measures of PSS. Direct associations between race/ethnicity and each outcome were estimated along with all indirect associations through unmet social support needs and SEP. The figure below represents the path diagram corresponding to the structural equation model. Probit models for binary dependent variables (unmet social support) and linear regressions for continuous PSS dependent variables were estimated using full information maximum likelihood to account for missing data (MAR assumption). All models were adjusted for age (not shown in Fig. 1).

Each of the three continuous PSS variables were modeled as dependent variables in linear regression against unmet social support variables, continuous SEP, indicator variables for nH AA and Hispanic race/ethnicity, and age (continuous). Each of the five unmet support needs variables were modeled as dependent variables in probit regression against continuous SEP, indicator variables for $\mathrm{nH}$ AA and Hispanic race/ethnicity, and age. SEP was modeled in linear regression as a dependent variable against indicator variables for nH AA and Hispanic race/ethnicity, and age.

Indirect associations for racial/ethnic disparities in PSS variables as mediated by unmet support needs and SEP were obtained by taking the product of coefficients within each path from race/ethnicity to specific PSS variable. We then calculated the proportion of the racial/ethnic disparities in PSS independently explained by unmet social support needs domains and SEP. The proportion mediated was independently calculated as the association of the indirect association divided by the total association. This was calculated for all possible indirect pathways. A mediation proportion of greater than $100 \%$ occurred when control for a mediator changed the sign of the coefficient of interest, which may have happened for substantive reasons or simply due to the typical instability of the resulting associations.

\section{Results}

\section{Descriptive analysis}

Table 1 shows racial/ethnic differences in sociodemographic and selected patient characteristics. Overall, mean age was similar for all racial/ethnic groups $(56 \pm 0.56,57 \pm 0.55$ and $54 \pm 0.86$ for $\mathrm{nH}$ White, $\mathrm{nH}$ AA and Hispanics, respectively). $\mathrm{nH}$ AA were more likely to live in disadvantage when compared to $\mathrm{nH}$ Whites and Hispanic women $(43.1 \%$ versus $1.16 \%$ and $6 \%$, respectively), whereas Hispanic participants reported lower education and were more likely to be uninsured (44\% less than high school and 25\% uninsured) when compared to $\mathrm{nH}$ Whites $(5 \%$ less than high school and $6 \%$ uninsured) and $\mathrm{nH}$ AA (19\% less than high school and $15 \%$ uninsured) $(p<0.0001$ and $p<0.001$, respectively). 
Table 1 Racial/ethnic differences in social support, sociodemogaphic, and clinical factors

\begin{tabular}{|c|c|c|c|c|c|}
\hline & $N$ & $\begin{array}{l}\text { nH White } \\
(n=397) \\
\%\end{array}$ & $\begin{array}{l}\text { nH Black } \\
(n=411) \\
\%\end{array}$ & $\begin{array}{l}\text { Hispanic } \\
(n=181) \\
\%\end{array}$ & $p$ value \\
\hline \multicolumn{6}{|l|}{ Age at diagnosis } \\
\hline $25-39$ & 66 & 6 & 6 & 9 & 0.97 \\
\hline $40-49$ & 236 & 25 & 22 & 24 & \\
\hline $50-59$ & 307 & 31 & 31 & 32 & \\
\hline $60-69$ & 246 & 24 & 26 & 24 & \\
\hline $70-79$ & 134 & 14 & 15 & 10 & \\
\hline \multicolumn{6}{|l|}{ Education } \\
\hline$<12$ & 176 & 5 & 19 & 44 & $<0.0001$ \\
\hline 12 & 193 & 13 & 25 & 22 & \\
\hline$>12$ & 617 & 82 & 56 & 35 & \\
\hline \multicolumn{6}{|l|}{ Income } \\
\hline$<20,000$ & 262 & 11 & 38 & 38 & $<0.0001$ \\
\hline$<75,000$ & 439 & 40 & 50 & 50 & \\
\hline$>75,000$ & 259 & 49 & 13 & 12 & \\
\hline \multicolumn{6}{|l|}{ Insurance } \\
\hline No outpatient insurance & 128 & 6 & 15 & 25 & $<0.001$ \\
\hline Public insurance only & 164 & 4 & 26 & 22 & \\
\hline Private & 697 & 90 & 59 & 53 & \\
\hline \multicolumn{6}{|l|}{ Concentrated affluence } \\
\hline$<1 \mathrm{SD}$ below mean & 65 & 1 & 10 & 11 & $<0.0001$ \\
\hline Within 1 SD of mean & 729 & 59 & 83 & 85 & \\
\hline$>1 \mathrm{SD}$ above mean & 193 & 40 & 7 & 4 & \\
\hline \multicolumn{6}{|l|}{ Concentrated disadvantage } \\
\hline$<1 \mathrm{SD}$ below mean & 142 & 31 & 1 & 7 & $<0.0001$ \\
\hline Within 1 SD of mean & 652 & 67 & 56 & 87 & \\
\hline$>1 \mathrm{SD}$ above mean & 57 & 7 & 43 & 3 & \\
\hline \multicolumn{6}{|l|}{ Stage } \\
\hline 0 & 200 & 27 & 23 & 16 & $<0.0001$ \\
\hline 1 & 289 & 38 & 31 & 30 & \\
\hline 2 & 255 & 26 & 31 & 36 & \\
\hline 4 & 43 & 3 & 5 & 5 & \\
\hline \multicolumn{6}{|l|}{ Initiated radiation } \\
\hline No & 484 & 43 & 56 & 46 & $<0.01$ \\
\hline Yes & 503 & 57 & 44 & 54 & \\
\hline \multicolumn{6}{|l|}{ Initiated chemotherapy } \\
\hline No & 573 & 67 & 52 & 52 & $<0.0001$ \\
\hline Yes & 414 & 33 & 48 & 48 & \\
\hline \multicolumn{6}{|l|}{ Initiated hormone therapy } \\
\hline No & 711 & 69 & 77 & 68 & 0.01779 \\
\hline Somewhat/not at all & 171 & 11 & 19 & 27 & \\
\hline \multicolumn{6}{|l|}{ Unmet emotional support } \\
\hline No & 905 & 95 & 90 & 87 & $<0.0001$ \\
\hline Yes & 84 & 5 & 10 & 13 & \\
\hline \multicolumn{6}{|l|}{ Unmet spiritual support } \\
\hline No & 861 & 87 & 90 & 81 & 0.009 \\
\hline Yes & 127 & 13 & 10 & 19 & \\
\hline \multicolumn{6}{|l|}{ Unmet informational support } \\
\hline No & 857 & 91 & 85 & 81 & $<0.001$ \\
\hline Yes & 132 & 9 & 15 & 19 & \\
\hline
\end{tabular}


Table 1 (continued)

\begin{tabular}{llllll}
\hline & $N$ & $\begin{array}{l}\text { nH White } \\
(n=397) \\
\%\end{array}$ & $\begin{array}{l}\text { nH Black } \\
(n=411) \\
\%\end{array}$ & $\begin{array}{l}\text { Hispanic } \\
(n=181) \\
\%\end{array}$ & $p$ value \\
& & & & & \\
\hline Unmet financial support & 721 & 84 & 64 & 69 & $<0.0001$ \\
No & 268 & 16 & 36 & 31 & $<0.0001$ \\
Yes & & & & 86 & \\
Unmet practical support & 871 & 93 & 84 & 14 & \\
No & 118 & 7 & 16 & & \\
Yes & & & & & \\
\hline
\end{tabular}

Both nH AA (38\%) and Hispanic (38\%) women reported lower annual income when compared to $\mathrm{nH}$ Whites (11\%) $(p<0.0001)$ (Table 1). In terms of unmet social support, $\mathrm{nH}$ AA and Hispanic patients were more likely to have unmet financial, emotional and practical support than $\mathrm{nL}$ Whites $(p<0.001)$. In addition, Hispanic patients were more likely to have unmet 1 , spiritual and informational support when compared to $\mathrm{nH}$ Whites $(p<0.001)$.

Overall, younger patients, racial/ethnic minorities and patients with lower socioeconomic position reported a higher prevalence of PSS (Table 2). Later stage at diagnosis was associated with greater perceived stress and greater psychological consequences ( $p_{\text {trend }}<0.001$ and $<0.0001$, respectively). For each of the five measures of unmet support needs and for each of the three measures of PSS, greater unmet need was associated with greater PSS (Table 2).

Results from our Y-standardized linear models showed that for all three PSS measures and for both nH AA and Hispanic versus nH White patients, controlling for SES either eliminated or greatly attenuated associations of race/ethnicity with PSS (Table 3). For example, for loneliness among nH AA, the age-adjusted standardized Beta changed from $\beta_{\text {STDY: }} 0.1133(p<0.001)$ to $\beta_{\text {STDY }}-0.0629(p=0.16)$ after including SES in the model.

\section{Path models}

The model fit statistics for this path model indicated a good fitting model $(\mathrm{CFI}=1.000, \mathrm{RMSEA}=0.036, p$ value from $\chi^{2}$ Test of Model Fit $=0.14$ ). From this model, we first estimated indirect associations for SEP and unmet support needs, and the proportion of each disparities that was independently mediated by SEP and unmet support needs.

SEP accounted for most of the nH AA-nH White disparities in PSS, including in psychological consequences, perceived stress, and loneliness (proportion mediated $\geq 86 \%$ ). There were no mediating effects of unmet social support needs on PSS that were independent of SEP. However, a large proportion of the statistical mediation by SEP was the result of further mediation by unmet financial and practical needs within the nH AA-nH White disparity (Table 4).

SEP similarly accounted for most of the Hispanic-nH White disparity in PSS, including $69 \%$ of the disparity in psychological consequences, $46 \%$ in perceived stress and $94 \%$ in loneliness. There were no mediating effects of unmet social support needs on PSS that were independent of SEP. However, a substantial portion of the statistical mediation by SEP was due to unmet emotional needs (Table 5). Finally, we ran a sensitivity analysis excluding women below $40 \mathrm{y} / \mathrm{o}$ $(n=66)$, the age which women begin mammogram screening, and no differences were observed in our results (Data not shown).

\section{Discussion}

Our study adds to a growing body of literature that directly quantifies underlying mechanisms of racial/ethnic disparities in PSS among breast cancer patients. We found that SEP mediated virtually all of the racial/ethnic disparity in our three PSS measures for both NHB and Hispanic patients. Part of this mediation of SEP was further mediated by unmet social support needs, but in a different way for NHB and Hispanic patients. Greater unmet financial and practical support needs each accounted for between roughly one-tenth and one-fifth of the NHB, NHW disparity across the three PSS measures; in contrast, greater unmet emotional support needs accounted for between roughly one-fifth to one-fourth of the Hispanic, NHW disparity in PSS.

Our first finding aligns with a large body of research clarifying that racial/ethnic minorities are particularly vulnerable to financial strain pre and post cancer diagnosis [18-22]. Specifically, our study found racial/ethnic differences in financial strain that are consistent with existing literature. Where, in general and pre-cancer diagnosis, Hispanic and $\mathrm{nH}$ AAs are more likely to have poor SEP at the individual (e.g., lack health insurance, have lower income, lower educational status) and neighborhood-level (e.g., medical deserts, concentrated poverty) when compared to $\mathrm{nH}$ Whites [28-30]. It is thus not surprising that non-Hispanic and $\mathrm{nH}$ 
Table 2 Differences in the prevalence of self-reported psychosocial stress, defined as reporting values above the sample median, by sociodemogaphic and clinical factors

\begin{tabular}{|c|c|c|c|c|c|c|}
\hline & \multicolumn{2}{|c|}{ Loneliness } & \multicolumn{2}{|c|}{ Perceived stress } & \multicolumn{2}{|c|}{$\begin{array}{l}\text { Psychological conse- } \\
\text { quences }\end{array}$} \\
\hline & $\%$ & $p$ value & $\%$ & $p$ value & $\%$ & $p$ value \\
\hline Race/ethnicity & & 0.0009 & & $<0.0001$ & & 0.075 \\
\hline $\mathrm{nH}$ white & 28 & & 38 & & 41 & \\
\hline nH black & 37 & & 48 & & 44 & \\
\hline Hispanic & 43 & & 60 & & 51 & \\
\hline Age at diagnosis & & 0.05 & & $<0.0001$ & & $<0.0001$ \\
\hline $25-39$ & 46 & & 58 & & 68 & \\
\hline $40-49$ & 35 & & 54 & & 53 & \\
\hline $50-59$ & 38 & & 52 & & 50 & \\
\hline $60-69$ & 33 & & 38 & & 34 & \\
\hline $70-79$ & 24 & & 28 & & 20 & \\
\hline Education & & 0.00005 & & $<0.0001$ & & 0.06 \\
\hline$<12$ & 47 & & 63 & & 49 & \\
\hline 12 & 37 & & 45 & & 46 & \\
\hline$>12$ & 30 & & 42 & & 42 & \\
\hline Income & & $<0.0001$ & & $<0.0001$ & & 0.02 \\
\hline$<20,000$ & 50 & & 58 & & 51 & \\
\hline$<75,000$ & 38 & & 47 & & 43 & \\
\hline$>75,000$ & 17 & & 33 & & 40 & \\
\hline Insurance & & $<0.0001$ & & $<0.0001$ & & $<0.00001$ \\
\hline No outpatient insurance & 46 & & 66 & & 59 & \\
\hline Public insurance only & 46 & & 59 & & 51 & \\
\hline Private & 30 & & 39 & & 39 & \\
\hline Concentrated disadvantage & & 0.03 & & 0.02 & & \\
\hline$<1 \mathrm{SD}$ below mean & 25 & & 34 & & 42 & \\
\hline Within 1 SD of mean & 36 & & 48 & & 44 & \\
\hline$>1 \mathrm{SD}$ above mean & 38 & & 48 & & 45 & \\
\hline Concentrated affluence & & 0.002 & & 0.01 & & \\
\hline$<1 \mathrm{SD}$ below mean & 38 & & 48 & & 46 & \\
\hline Within 1 SD of mean & 37 & & 48 & & 44 & \\
\hline$>1 \mathrm{SD}$ above mean & 24 & & 36 & & 42 & \\
\hline Stage at diagnosis & & & & 0.002 & & $<0.0001$ \\
\hline 0 & 34 & & 42 & & 35 & \\
\hline 1 & 35 & & 43 & & 38 & \\
\hline 2 & 36 & & 51 & & 55 & \\
\hline $3 / 4$ & 39 & & 58 & & 55 & \\
\hline \multicolumn{7}{|l|}{ Initiated radiation } \\
\hline No & 37 & & 47 & & 44 & \\
\hline Yes & 33 & & 45 & & 43 & \\
\hline Initiated chemotherapy & & & & 0.0003 & & $<0.0001$ \\
\hline No & 34 & & 41 & & 35 & \\
\hline Yes & 36 & & 53 & & 56 & \\
\hline Initiated hormone therapy & & & & 0.051 & & 0.0007 \\
\hline No & 34 & & 48 & & 47 & \\
\hline Yes & 36 & & 41 & & 35 & \\
\hline Unmet emotional support & & $<0.0001$ & & $<0.0001$ & & $<0.0001$ \\
\hline No & 31 & & 44 & & 41 & \\
\hline Yes & 79 & & 73 & & 73 & \\
\hline Unmet spiritual support & & $<0.0001$ & & $<0.0001$ & & $<0.0001$ \\
\hline No & 31 & & 44 & & 41 & \\
\hline
\end{tabular}


Table 2 (continued)

\begin{tabular}{|c|c|c|c|c|c|c|}
\hline & \multicolumn{2}{|c|}{ Loneliness } & \multicolumn{2}{|c|}{ Perceived stress } & \multicolumn{2}{|c|}{$\begin{array}{l}\text { Psychological conse- } \\
\text { quences }\end{array}$} \\
\hline & $\%$ & $p$ value & $\%$ & $p$ value & $\%$ & $p$ value \\
\hline Yes & 57 & & 61 & & 67 & \\
\hline Unmet informational support & & $<0.0001$ & & 0.001 & & $<0.0001$ \\
\hline No & 32 & & 44 & & 41 & \\
\hline Yes & 56 & & 59 & & 63 & \\
\hline Unmet financial support & & $<0.0001$ & & $<0.0001$ & & $<0.0001$ \\
\hline No & 30 & & 39 & & 38 & \\
\hline Yes & 49 & & 64 & & 60 & \\
\hline Unmet practical support & & $<0.0001$ & & $<0.0001$ & & $<0.0001$ \\
\hline No & 31 & & 43 & & 41 & \\
\hline Yes & 63 & & 71 & & 67 & \\
\hline
\end{tabular}

Table 3 Associations between race/ethnicity and PSS before and after adjusting for SES

\begin{tabular}{llcl}
\hline & Adjusted for & Beta(STDY) & $p$ value \\
\hline Loneliness & & & \\
nH AA & Age & 0.1133 & 0.001 \\
nHAA & Age, SES & -0.0629 & 0.16 \\
Hispanic & Age & 0.1531 & 0.0000 \\
Hispanic & Age, SES & 0.0221 & 0.58 \\
Stress & & & \\
nH AA & Age & 0.0985 & 0.0040 \\
nHAA & Age, SES & -0.0226 & 0.61 \\
Hispanic & Age & 0.1485 & 0.0000 \\
Hispanic & Age, SES & 0.0585 & 0.14 \\
Consequences & & & \\
nH AA & Age & 0.0956 & 0.006 \\
nHAA & Age, SES & -0.0089 & 0.85 \\
Hispanic & Age & 0.1110 & 0.001 \\
Hispanic & Age, SES & 0.0344 & 0.40 \\
\hline
\end{tabular}

AAs experience greater financial burden from cancer diagnoses than $\mathrm{nH}$ White women [31, 32]. Simultaneously, low SEP, especially when operationalized at multiple levelsi.e., composites that include both individual- and neighborhood-level aspects-has been associated with worse PSS and physical health outcomes [25, 33, 34].

Our novel approach clarified past conflicting research [9-11]. Specifically, existing work that has considered SEP and unmet social support needs simultaneously has been mixed, with some studies suggesting that unmet social support needs explain more of racial/ethnic cancer disparities [10], other work suggesting SEP explains more of racial/ ethnic disparities [11], and other work has suggested both are important [17]. For example, two previous studies used our same data source, SEP, and unmet social support measures $[10,11]$. Using the same dataset that we used, Tejeda et al. summed the 5 variables for support needed and again for support received then calculated the difference between needed and received support to create a
Fig. 1 Path diagram corresponding to the path analysis. Dashed arrows represent direct associations for race/ethnicity with unmet support needs not mediated by SEP. Race/ethnicity was specified as two indicator variables for $\mathrm{nH}$ AA and Hispanic (nH white as referent)

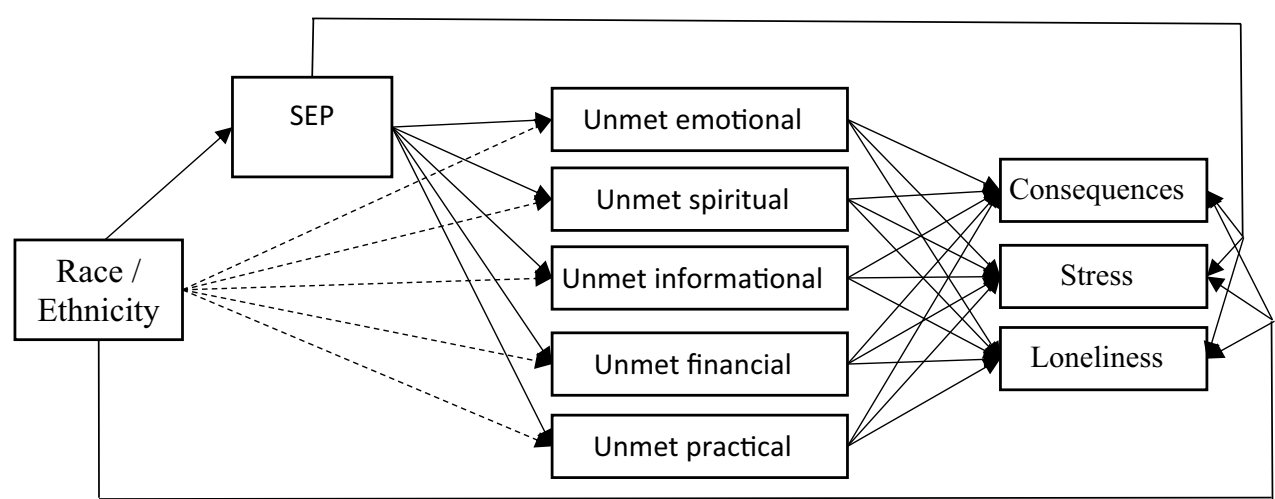


Table 4 Path model for socioeconomic status and psychosocial stress in mediating the $\mathrm{nH}$ Black and $\mathrm{nH}$ White disparity in psychosocial stress in the Breast Cancer Care in Chicago

\begin{tabular}{|c|c|c|c|c|c|c|c|c|c|}
\hline & \multicolumn{3}{|c|}{$\begin{array}{l}\text { Pychological conse- } \\
\text { quences }\end{array}$} & \multicolumn{3}{|c|}{ Perceived stress } & \multicolumn{3}{|c|}{ Loneliness } \\
\hline & Value & $p$ value & $p$ value & Value & $p$ value & $p$ value & Value & $p$ value & $p$ value \\
\hline $\begin{array}{l}\text { Total association } \\
\text { (fully standardized) }\end{array}$ & 0.110 & 0.003 & 0.001 & 0.085 & 0.016 & 0.02 & 0.110 & 0.003 & 0.001 \\
\hline Proportion mediated & $95 \%$ & 0.026 & 0.03 & $86 \%$ & 0.014 & 0.01 & $164 \%$ & 0.004 & 0.004 \\
\hline \multicolumn{10}{|l|}{ Through SES } \\
\hline Overall & $109 \%$ & 0.034 & 0.03 & $102 \%$ & 0.031 & 0.03 & $174 \%$ & 0.007 & 0.007 \\
\hline Via unmet needs & $52 \%$ & 0.136 & 0.14 & $34 \%$ & 0.055 & 0.06 & $125 \%$ & 0.011 & 0.01 \\
\hline Not via unmet needs & $57 \%$ & 0.027 & 0.03 & $68 \%$ & 0.032 & 0.03 & $49 \%$ & 0.019 & 0.02 \\
\hline \multicolumn{10}{|l|}{ Through unmet needs } \\
\hline Overall & $43 \%$ & 0.02 & 0.02 & $52 \%$ & 0.022 & 0.02 & $39 \%$ & 0.015 & 0.02 \\
\hline \multicolumn{10}{|c|}{ Through individual unmet needs } \\
\hline Emotional & $11 \%$ & 0.295 & 0.30 & $11 \%$ & 0.305 & 0.31 & $10 \%$ & 0.307 & 0.31 \\
\hline Spiritual & $3 \%$ & 0.547 & 0.55 & $3 \%$ & 0.548 & 0.55 & $1 \%$ & 0.566 & 0.57 \\
\hline Informational & $4 \%$ & 0.225 & 0.23 & $-3 \%$ & 0.341 & 0.34 & $1 \%$ & 0.606 & 0.61 \\
\hline Financial & $17 \%$ & 0.061 & 0.06 & $23 \%$ & 0.057 & 0.06 & $13 \%$ & 0.089 & 0.09 \\
\hline Practical & $9 \%$ & 0.116 & 0.12 & $19 \%$ & 0.06 & 0.06 & $14 \%$ & 0.042 & 0.04 \\
\hline
\end{tabular}

Estimates and $p$ values are suppressed when the proportion mediated is $<5 \%$ or the corresponding $p$ value $>0.20$

Table 5 Path model for socioeconomic status and psychosocial stress in mediating the Hispanic and nH White disparity in psychosocial stress in the Breast Cancer Care in Chicago

\begin{tabular}{|c|c|c|c|c|c|c|c|c|c|}
\hline & \multicolumn{3}{|c|}{ Pychological consequences } & \multicolumn{3}{|c|}{ Perceived stress } & \multicolumn{3}{|c|}{ Loneliness } \\
\hline & Value & $p$ value & $p$ value & Value & $p$ value & $p$ value & Value & $p$ value & $p$ value \\
\hline Total association (fully standardized) & 0.112 & 0.001 & 0.001 & 0.138 & & $<0.0001$ & 0.150 & & $<0.0001$ \\
\hline Proportion mediated & $80 \%$ & 0.006 & 0.01 & $44 \%$ & 0.002 & 0.002 & $98 \%$ & 0 & $<0.0001$ \\
\hline \multicolumn{10}{|l|}{ Through SES } \\
\hline Overall & $69 \%$ & 0.018 & 0.02 & $46 \%$ & 0.003 & 0.003 & $94 \%$ & 0 & $<0.0001$ \\
\hline Via unmet needs & $33 \%$ & 0.116 & 0.12 & $15 \%$ & 0.014 & 0.01 & $67 \%$ & 0.001 & 0.001 \\
\hline Not via unmet needs & $36 \%$ & 0.013 & 0.01 & $31 \%$ & 0.003 & 0.003 & $26 \%$ & 0.003 & 0.003 \\
\hline Through unmet needs & & & 0.00 & & & & & & \\
\hline Overall & $47 \%$ & 0.003 & 0.00 & $28 \%$ & 0.012 & 0.01 & $31 \%$ & 0.002 & 0.002 \\
\hline Through individual unmnt needs & & & 0.00 & & & & & & \\
\hline Emotional & $25 \%$ & 0.014 & 0.01 & $17 \%$ & 0.013 & 0.01 & $19 \%$ & 0.008 & 0.01 \\
\hline Spiritual & $7 \%$ & 0.123 & 0.12 & $5 \%$ & 0.128 & 0.13 & $3 \%$ & 0.206 & 0.21 \\
\hline Informational & $8 \%$ & 0.104 & 0.10 & $-4 \%$ & 0.229 & 0.23 & $1 \%$ & 0.586 & 0.59 \\
\hline Financial & $6 \%$ & 0.139 & 0.14 & $6 \%$ & 0.117 & 0.12 & $4 \%$ & 0.169 & 0.17 \\
\hline Practical & $3 \%$ & 0.328 & 0.33 & $4 \%$ & 0.297 & 0.30 & $4 \%$ & 0.281 & 0.28 \\
\hline
\end{tabular}

Estimates and $p$ values are suppressed when the proportion mediated is $<5 \%$ or the corresponding $p$ value $>0.20$

continuous variable for unmet social support. Unmet support needs were the strongest mediator of racial/ethnic disparities in one of the PSS measures used in our study (psychological consequences after a BC diagnosis) [10]. Our study expanded on this study by tearing apart the five dimensions of unmet needs and the intertwined roles that SES and unmet needs play in mediating racial/ethnic disparities in PSS, and by including two additional measures of PSS. A second analyses of these data by Vijasayisiri et al. focused on BC-specific survival and did not examine PSS as either a dependent or independent variable. Neighborhood-concentrated disadvantage (one component of our SES measure) was associated with worse survival, whereas social network size and density, as well as practical and financial support were each associated with improved 5-year survival. Neighborhood-concentrated disadvantage and practical support 
each mediated a portion of the $\mathrm{nH}$ AA- $\mathrm{nH}$ White survival disparity.

On the other hand, the study by Thompson et al., used a smaller sample of $n=229 \mathrm{nH}$ AA newly BC diagnosed women to evaluate: ((a) associations of initial levels of perceived social support with demographic and clinical factors and (b) associations of perceived social support with depressive symptoms after adjusting by individual level sociodemographic and clinical covariates [35]. Contrary to our study: (1) Thompson et al., evaluated changes in social support post diagnosis and after a 2 year follow-up period using the Medical Outcomes Study Social Support Survey (MOS-SSS). Similar to our findings, after including SES in their models, the association of perceived social support with depressive symptoms was attenuated, which is consistent with a role for SES in mediating the association of social support with depressive symptoms.

Our work highlights how SEP may result in lower PSS through unmet social support, in line with extant theoretical frameworks $[11,12,14,16]$. Further, our consideration of different social support domains adds to a large, complicated picture of racial/ethnic differences in social support [10, 36-38] by clarifying the specific domains of support through which SEP results in PSS disparities. For nH AA patients, our work suggests interventions that provide explicit, concrete financial support may be particularly helpful to address patients' objective needs and perceptions about available financial resources. For Hispanic patients, our findings suggest that financial toxicity may subsequently lead to unmet emotional support. This relationship may be understood in the context of family dynamics, wherein patients belong to a culture that values social collectivism and interdependence, and may perceive themselves to be unduly burdensome to their family and friends because of their cancer diagnosis and its associated costs [39]. Notably, neither informational support nor spiritual support displayed an independent or interdependent mediating effect on the association between SEP and PSS.

This secondary data analysis has some limitations. First, we had a relatively small sample size, specifically for the Hispanic group, which may have impacted the precision of our estimates. Second, due to the cross-sectional design SEP, unmet social support needs and PSS were measured at the point in time post diagnosis. We assumed a causal ordering in our analyses such that SEP preceded unmet social support needs which preceded PSS. While these assumptions are theoretically reasonable, they were likely violated to an extent by our design. For example, SEP as measured might not reflect pre-diagnostic SEP if a diagnosis caused the loss of a job or other life event that created economic hardship affecting household income. Relatedly, while we assumed that unmet social support needs preceded PSS, increased levels of PSS resulting from a diagnosis could cause social network members to withdraw from the patients, producing an association due to reverse causality. Additionally, a patient experiencing high levels of PSS might perceive a higher level of unmet social support needs independent of the actual extent of support provided to her. A third limitation is the way we operationalized SEP, where we assumed equal impacts of contextual and individual level variables. However, contextual SEP theoretically predicts individual SES and may be more impactful as a root cause of unmet support needs and PSS. Our approach addresses an emergent need in the literature: future work should provide theorydriven guidance for multi-level SEP measurement (e.g., how and when to weight contextual versus individual level SES variables). Additionally, age categories were based on available sample characteristics. We ran a sensitivity where we excluded participants younger than 40y/o and we didn't observe significant differences in the results from our path models. Fourth, future studies that distinguish between screening-eligible and younger populations are critical. Since women younger than $40 \mathrm{y} / \mathrm{o}$ are more likely to have children and may experience negative impacts of treatments on fertility-which has been associated to PSS. Finally, we used single-item measures for the different social support domains; while these measures have been previously used, there is a need to replicate our work with validated, commonly used multi-item measures (e.g., Medical Outcomes Study Social Support Survey MOS-SSS).

\section{Implications}

Our findings are timely, given the increasing attention paid to developing financial support resources for cancer survivors overall [40-42]. Financial navigation and other types of interventions may be particularly useful for mitigating racial/ ethnic disparities in PSS, given the large independent mediating role of SEP. Simultaneously, our work has the potential to help researchers develop prevention and intervention strategies, focusing in financial support for nHAA and in practical and emotional support for Hispanics. These, in turn, could be used to help eliminate cancer health disparities.

Author contributions All authors contributed to the study conception. Data analysis was performed by CSD and GR. The first draft of the manuscript was written by CSD, YM, and GR. GV, ST, and SS reviewed and provided comments on all versions of the manuscript. All authors read and approved the final manuscript.

Funding This work was funded by NIH 2T32 CA057699-28 and a Susan G. Komen Foundation training grant (G3143).

Code availability For this study, the authors used Mplus 8 and Stata 15.1 for the analysis. 
Data availability Data were obtained from the Breast Cancer Care in Chicago and the study was approved by the University of Illinois at Chicago Institutional Review Board.

\section{Compliance with ethical standards}

Conflict of interest The authors declare no potential conflict of interest.

Open Access This article is licensed under a Creative Commons Attribution 4.0 International License, which permits use, sharing, adaptation, distribution and reproduction in any medium or format, as long as you give appropriate credit to the original author(s) and the source, provide a link to the Creative Commons licence, and indicate if changes were made. The images or other third party material in this article are included in the article's Creative Commons licence, unless indicated otherwise in a credit line to the material. If material is not included in the article's Creative Commons licence and your intended use is not permitted by statutory regulation or exceeds the permitted use, you will need to obtain permission directly from the copyright holder. To view a copy of this licence, visit http://creativecommons.org/licenses/by/4.0/.

\section{References}

1. Chrousos GP, Torpy DJ, Gold PW (1998) Interactions between the hypothalamic-pituitary-adrenal axis and the female reproductive system: clinical implications. Ann Intern Med 129(3):229-240

2. Andersen BL, Kiecolt-Glaser JK, Glaser R (1994) A biobehavioral model of cancer stress and disease course. Am Psychol 49(5):389-404

3. Russell KM, Von Ah DM, Giesler RB, Storniolo AM, Haase JE (2008) Quality of life of African American breast cancer survivors: how much do we know? Cancer Nurs 31(6):E36-45. https:// doi.org/10.1097/01.NCC.0000339254.68324.d7

4. Sammarco A, Konecny LM (2010) Quality of life, social support, and uncertainty among Latina and Caucasian breast cancer survivors: a comparative study. Oncol Nurs Forum 37(1):93-99. https://doi.org/10.1188/10.ONF.93-99

5. Powe BD et al (2007) Quality of life of African American cancer survivors. A review of the literature. Cancer 109(2 Suppl):435445. https://doi.org/10.1002/cncr.22358

6. Yanez B, Thompson EH, Stanton AL (2011) Quality of life among Latina breast cancer patients: a systematic review of the literature. J Cancer Surviv Res Pract 5(2):191-207. https://doi.org/10.1007/ s11764-011-0171-0

7. Singh GK, Williams SD, Siahpush M, Mulhollen A (2011) Socioeconomic, rural-urban, and racial inequalities in US cancer mortality: part I-all cancers and lung cancer and part II-colorectal, prostate, breast, and cervical cancers. J Cancer Epidemiol 2011:1-27. https://doi.org/10.1155/2011/107497

8. Paskett ED et al (2008) Breast cancer survivors' health-related quality of life : racial differences and comparisons with noncancer controls. Cancer 113(11):3222-3230. https://doi.org/10.1002/ cncr.23891

9. Pinheiro LC, Samuel CA, Reeder-Hayes KE, Wheeler SB, Olshan AF, Reeve BB (2016) Understanding racial differences in healthrelated quality of life in a population-based cohort of breast cancer survivors. Breast Cancer Res Treat 159(3):535-543. https://doi. org/10.1007/s10549-016-3965-y

10. Tejeda $S$ et al (2017) Negative psychological consequences of breast cancer among recently diagnosed ethnically diverse women.
Psychooncology 26(12):2245-2252. https://doi.org/10.1002/ pon.4456

11. Vijayasiri G, Molina Y, Chukwudozie IB, Tejeda S, Pauls H, Rauscher G, Campbell RT, Warnecke RB (2018) Racial disparities in breast cancer survival: the mediating effects of macro-social context and social network factors. J Health Disparities Res Pract 11(3):6

12. Warnecke RB et al (2008) Approaching health disparities from a population perspective: the national institutes of health centers for population health and health disparities. Am J Public Health 98(9):1608-1615. https://doi.org/10.2105/AJPH.2006.102525

13. Yanez B, McGinty HL, Buitrago D, Ramirez AG, Penedo FJ (2016) Cancer outcomes in hispanics/latinos in the United States: an integrative review and conceptual model of determinants of health. J Lat Psychol 4(2):114-129. https://doi.org/10.1037/lat00 00055

14. Krieger N, Williams DR, Moss NE (1997) Measuring social class in US public health research: concepts, methodologies, and guidelines. Annu Rev Public Health 18:341-378. https:// doi.org/10.1146/annurev.publhealth.18.1.341

15. Lynch JW, Smith GD, Kaplan GA, House JS (2000) Income inequality and mortality: importance to health of individual income, psychosocial environment, or material conditions. BMJ 320(7243):1200-1204. https://doi.org/10.1136/ bmj.320.7243.1200

16. Helgeson VS, Cohen S (1999) Social support and adjustment to cancer: reconciling descriptive, correlational, and intervention research. In: Suinn RM, VandenBos GR (eds) Cancer patients and their families: readings on disease course, coping, and psychological interventions. American Psychological Association, Washington, pp 53-79

17. Yu Q, Medeiros KL, Wu X, Jensen RE (2018) Nonlinear predictive models for multiple mediation analysis: with an application to explore ethnic disparities in anxiety and depression among cancer survivors. Psychometrika 83(4):991-1006. https://doi. org/10.1007/s11336-018-9612-2

18. Evans GW, Kim P (2010) Multiple risk exposure as a potential explanatory mechanism for the socioeconomic status-health gradient. Ann N Y Acad Sci 1186:174-189. https://doi.org/10. 1111/j.1749-6632.2009.05336.x

19. Rauscher GH, Campbell RT, Wiley EL, Hoskins K, Stolley MR, Warnecke RB (2016) Mediation of racial and ethnic disparities in estrogen/progesterone receptor-negative breast cancer by socioeconomic position and reproductive factors. Am J Epidemiol 183(10):884-893. https://doi.org/10.1093/aje/kwv226

20. Warnecke RB, Campbell RT, Vijayasiri G, Barrett RE, Rauscher GH (2019) Multilevel examination of health disparity: the role of policy implementation in neighborhood context, in patient resources, and in healthcare facilities on later stage of breast cancer diagnosis. Cancer Epidemiol Biomark Prev 28(1):59-66. https://doi.org/10.1158/1055-9965.EPI-17-0945

21. Cohen S, Kamarck T, Mermelstein R (1983) A global measure of perceived stress. J Health Soc Behav 24(4):385-396

22. Karam F et al (2012) Reliability and validity of the 4-item perceived stress scale among pregnant women: results from the OTIS antidepressants study. Res Nurs Health 35(4):363-375. https://doi.org/10.1002/nur.21482

23. Hughes ME, Waite LJ, Hawkley LC, Cacioppo JT (2004) A short scale for measuring loneliness in large surveys: results from two population-based studies. Res Aging 26(6):655-672. https://doi.org/10.1177/0164027504268574

24. Cockburn J, De Luise T, Hurley S, Clover K (1992) Development and validation of the PCQ: a questionnaire to measure the psychological consequences of screening mammography. Soc Sci Med 34(10):1129-1134 
25. Parise CA, Caggiano V (2013) Disparities in race/ethnicity and socioeconomic status: risk of mortality of breast cancer patients in the California Cancer Registry, 2000-2010. BMC Cancer 13:449. https://doi.org/10.1186/1471-2407-13-449

26. Silva A, Rauscher GH, Ferrans CE, Hoskins K, Rao R (2014) Assessing the quality of race/ethnicity, tumor, and breast cancer treatment information in a non-SEER state registry. J Regist Manag 41(1):24-30

27. MPlus. Los Angeles, California: Muthén and Muthén

28. DeNavas-Walt C (2010) Income, poverty, and health insurance coverage in the United States. Diane Publishing, Darby

29. Snowden L, Graaf G (2019) The 'undeserving poor', racial bias, and medicaid coverage of African Americans. J Black Psychol 45(3):130-142. https://doi.org/10.1177/0095798419844129

30. Mitra S, Brucker D (2019) Monitoring multidimensional poverty in the United States. Econ Bull 39:A122

31. Wheeler SB, Spencer JC, Pinheiro LC, Carey LA, Olshan AF, Reeder-Hayes KE (2018) Financial impact of breast cancer in Black versus White women. J Clin Oncol Off J Am Soc Clin Oncol 36(17):1695-1701. https://doi.org/10.1200/ JCO.2017.77.6310

32. Abbott DE, Voils CL, Fisher DA, Greenberg CC, Safdar N (2017) Socioeconomic disparities, financial toxicity, and opportunities for enhanced system efficiencies for patients with cancer. J Surg Oncol 115(3):250-256. https://doi.org/10.1002/jso.24528

33. Ashing-Giwa KT, Lim J (2009) Examining the impact of socioeconomic status and socioecologic stress on physical and mental health quality of life among breast cancer survivors. Oncol Nurs Forum 36(1):79-88. https://doi.org/10.1188/09.ONF.79-88

34. Muscatell KA (2018) Socioeconomic influences on brain function: implications for health. Ann N Y Acad Sci 1428(1):14-32. https ://doi.org/10.1111/nyas.13862

35. Thompson T, Pérez M, Kreuter M, Margenthaler J, Colditz G, Jeffe DB (2017) Perceived social support in African American breast cancer patients: predictors and effects. Soc Sci Med 192:134-142. https://doi.org/10.1016/j.socscimed.2017.09.035

36. Janz NK, Mujahid MS, Hawley ST, Griggs JJ, Hamilton AS, Katz SJ (2008) Racial/ethnic differences in adequacy of information and support for women with breast cancer. Cancer 113(5):10581067. https://doi.org/10.1002/cncr.23660

37. Molina $\mathrm{Y}$ et al (2016) Ethnic differences in social support after initial receipt of an abnormal mammogram. Cult Divers Ethnic Minor Psychol 22(4):588-593. https://doi.org/10.1037/cdp00 00098

38. Jutagir DR et al (2016) Ethnic differences in types of social support from multiple sources after breast cancer surgery. Ethn Health 21(5):411-425. https://doi.org/10.1080/13557858.2015.1066494

39. Gallo LC, Penedo FJ, K. Espinosa de los Monteros, and W. Arguelles, (2009) Resiliency in the face of disadvantage: do hispanic cultural characteristics protect health outcomes? J Pers 77(6):1707-1746. https://doi.org/10.111 1/j.1467-6494.2009.00598.x

40. Obeng-Gyasi S, Tolnitch L, Greenup RA, Hwang ES (2016) The impact of the affordable care act on north carolinian breast cancer patients seeking financial support for treatment. Ann Surg Oncol 23(10):3412-3417. https://doi.org/10.1245/s10434-016-5311-3

41. Davidoff AJ, Hill SC, Bernard D, Yabroff KR (2015) The affordable care act and expanded insurance eligibility among nonelderly adult cancer survivors. J Natl Cancer Inst. https://doi.org/10.1093/ jnci/djv181

42. Banegas MP et al (2019) The social and economic toll of cancer survivorship: a complex web of financial sacrifice. J Cancer Surviv Res Pract 13(3):406-417. https://doi.org/10.1007/s1176 4-019-00761-1

Publisher's Note Springer Nature remains neutral with regard to jurisdictional claims in published maps and institutional affiliations. 